\title{
Piezoelectric Properties of $\mathrm{PbNi}_{1 / 3} \mathrm{Nb}_{2 / 3} \mathrm{O}_{3}-\mathrm{PbTiO}_{3}-\mathrm{PbZrO}_{3}$ Ceramics Near the MPB
}

\author{
Masao KONDO, Masaharu HIDA, Mineharu TSUKADA, Kazuaki KURIHARA and Nobuo KAMEHARA \\ Fujitsu Laboratories Ltd., Inorganic Materials \& Polymers Laboratory, 10-1, Morinosato-Wakamiya, Atsugi-shi 243-01
}

\author{
$\mathrm{PbNi}_{1 / 3} \mathrm{Nb}_{2 / 3} \mathrm{O}_{3}-\mathrm{PbTiO}_{3}-\mathrm{PbZrO}_{3}$ セラミックスの相境界付近における圧電特性 \\ 近藤正雄・肥田勝春・塚田峰春・栗原和明・亀原伸男 \\ (侏富士通研究所材料技術研究所無機・高分子材料研究部, 243-01 神奈川県厚木市森の里若宮 10-1
}

\begin{abstract}
The change in the electromechanical coupling factor, $k_{33}$, was investigated as a function of $\mathrm{PbNi}_{1 / 3} \mathrm{Nb}_{2 / 3} \mathrm{O}_{3}$ $\mathrm{PbTiO}_{3}-\mathrm{PbZrO}_{3}$ (PNN-PT-PZ) piezoelectric ceramic composition near the morphotropic phase boundary. Ceramics were sintered both in air and in a powder-bed. The average grain size of the PNN-PT-PZ ceramics obtained by sintering in the powder-bed was larger than that in air. Utilizing the powder-bed sintering technique, a high performance PNN-PT-PZ ceramic with a $k_{33}$ of $80.8 \%$ was obtained.
\end{abstract}

[Received April 9, 1997; Accepted July 4, 1997]

Key-words : $\mathrm{PbNi}_{1 / 3} \mathrm{Nb}_{2 / 3} \mathrm{O}_{3}-\mathrm{PbTiO}_{3}-\mathrm{PbZrO}_{3}$, Piezoelectrics, Ceramics, Sintering, $k_{33}$

\section{Introduction}

Piezoelectrics are materials which have attracted much interest, both from fundamental and applied aspects, such as a multilayer ceramic actuator. Electromechanical coupling factor $(k)$ is the most important factor to evaluate the performance of piezoelectric ceramics. ${ }^{1)}$ This factor represents the conversion efficiency of electric energy into mechanical energy qualitatively. The factor has several different vibration modes. The 33 mode represents the strain direction which is parallel to the polar axis. The 33 mode $\left(k_{33}\right)$ is most important factor for multilayer ceramic actuators. ${ }^{2)}$

Lead-based perovskites are known to have excellent piezoelectric properties. For example, $\mathrm{Pb}(\mathrm{Zr}, \mathrm{Ti}) \mathrm{O}_{3}$ ceramics has the highest electromechanical coupling factor with a planar mode $\left(k_{\mathrm{p}}\right)$ of $77 \%$ in the piezoelectric ceramics. ${ }^{3)}$ $\mathrm{PbNi}_{1 / 3} \mathrm{Nb}_{2 / 3} \mathrm{O}_{3}-\mathrm{PbTiO}_{3}-\mathrm{PbZrO}_{3}$ (hereafter designated as PNN-PT-PZ) ceramics are also known to have high piezoelectric properties. The piezoelectric property of the $\mathrm{Pb}(\mathrm{Zr}$, Ti) $\mathrm{O}_{3}$ ceramics increases as the composition approaches the morphotropic phase boundary (MPB). Banno et al. formed the PNN-PT-PZ piezoelectric ceramics with the various compositions and determined the MPB composition of the PNN-PT-PZ system. ${ }^{4}$ The composition range investigated in their research was relatively large. The piezoelectric properties near the MPB composition are not clear, because their objective was to make a phase diagram. Luff et al. also investigated the change of the piezoelectric property with the composition and reported that the composition with the highest performance $\left(d_{33}=1100 \mathrm{pm} / \mathrm{V}\right)$ was $0.5 \mathrm{PNN}-0.35 \mathrm{PT}-0.15 \mathrm{PZ}$. ${ }^{5)}$ However, they did not report a change of $k_{33}$ with composition near MPB.

Other published research have focuses on the processing factors of PNN-PT-PZ ceramics, such as the influences of particle size of the calcined powder, ${ }^{6}$ ) of the additives $\left(\mathrm{CdO}, \mathrm{MnO}_{2}, \mathrm{SiO}_{2}\right),{ }^{7)}$ sintering atmosphere $\left(\mathrm{O}_{2}, \mathrm{~N}_{2} \text {, air }\right)^{8)}$ and so on. Thus, an investigation of the composition near the MPB has not yet been published in the research literature.

As a result in this study, the effect of the environment in the sintering process on grain growth was investigated. Then, the effect of composition on the piezoelectric ceramics particularly the $\mathrm{PZ} / \mathrm{PT}$ ratio near the MPB was investigated.

\section{Experimental}

Oxide powders of $\mathrm{PbO}, \mathrm{NiO}, \mathrm{Nb}_{2} \mathrm{O}_{5}, \mathrm{TiO}_{2}$ and $\mathrm{ZrO}_{2}$ of which purities are above $99.9 \%$ were used. $1 \mathrm{~mol} \mathrm{NiO}$ and $1 \mathrm{~mol} \mathrm{Nb} \mathrm{O}_{5}$ were mixed by ball milling for $20 \mathrm{~h}$. The mixture were calcined at $1000^{\circ} \mathrm{C}$ for $4 \mathrm{~h}$. The phase of the calcined powder, determined by X-ray diffraction (XRD) was single phase of $\mathrm{NiNb}_{2} \mathrm{O}_{6} . \mathrm{PbO}, \mathrm{NiNb}_{2} \mathrm{O}_{6}, \mathrm{TiO}_{2}$ and $\mathrm{ZrO}_{2}$ were mixed by ball milling for $20 \mathrm{~h}$. The mixtures were dried and calcined at $850-1100^{\circ} \mathrm{C}$ for $3-6 \mathrm{~h}$. The green compacts $(30 \mathrm{~mm} \phi \times 5 \mathrm{~mm})$ of the calcined powders were obtained by die pressing at $120-130 \mathrm{MPa}$ after an addition of a binder. The binder was burned out at $500^{\circ} \mathrm{C}$ for $1-3 \mathrm{~h}$. The green compacts were sintered at $1100^{\circ} \mathrm{C}$ for $3 \mathrm{~h}$ in air (closed container) or in the same composition powder (powder-bed method). The 33 mode specimens $(4 \times 4 \times 15 \mathrm{~mm})$ were made from the sintered bodies. The specimens were metallized with Ag paste and were poled under a DC field of $2 \mathrm{kV} / \mathrm{mm}$ at room temperature in a silicone oil bath.

The compositions of the calcined powders were measured by inductively coupled plasma atomic emission spectroscopy (ICP-AES). The molar regions of the composition at $\mathrm{PNN}=0.5, \quad 0.335<\mathrm{PT}<0.355$ and $0.145<\mathrm{PZ}$ $<0.165(0.408<\mathrm{PZ} / \mathrm{PT}<0.493)$. The compositions obtained by ICP-AES are almost the same as starting material composition.

The phase structure of PNN-PT-PZ ceramics was also established by X-ray diffraction (XRD) using $\mathrm{Cu} \mathrm{K} \alpha$. In order to carry out an accurate determination of the peak position $(2 \theta)$, the X-ray peaks were recorded step by step with $0.01^{\circ} /$ steps for a $5 \mathrm{~s}$ measuring period. The background and the diffraction of $K \alpha_{2}$ were removed from the peaks.

The densities of the piezoelectric ceramics were measured by the Archimedean method. The microstructure of fractured surface of the piezoelectric ceramics was observed by scanning electron microscope (SEM). Electromechanical coupling factor $\left(k_{33}\right)$ were measured by the resonant-antiresonant frequency method with an impedance analyzer.

\section{Results and discussion}

The XRD peaks of the (200) tetragonal, (002) tetragonal and (200) pseudocubic (rhombohedral) crystal occurred around $45^{\circ}$ in $2 \theta$ of the PNN-PT-PZ ceramics of which the composition is close to the MPB. ${ }^{7)}$ Figure 1 shows the XRD 


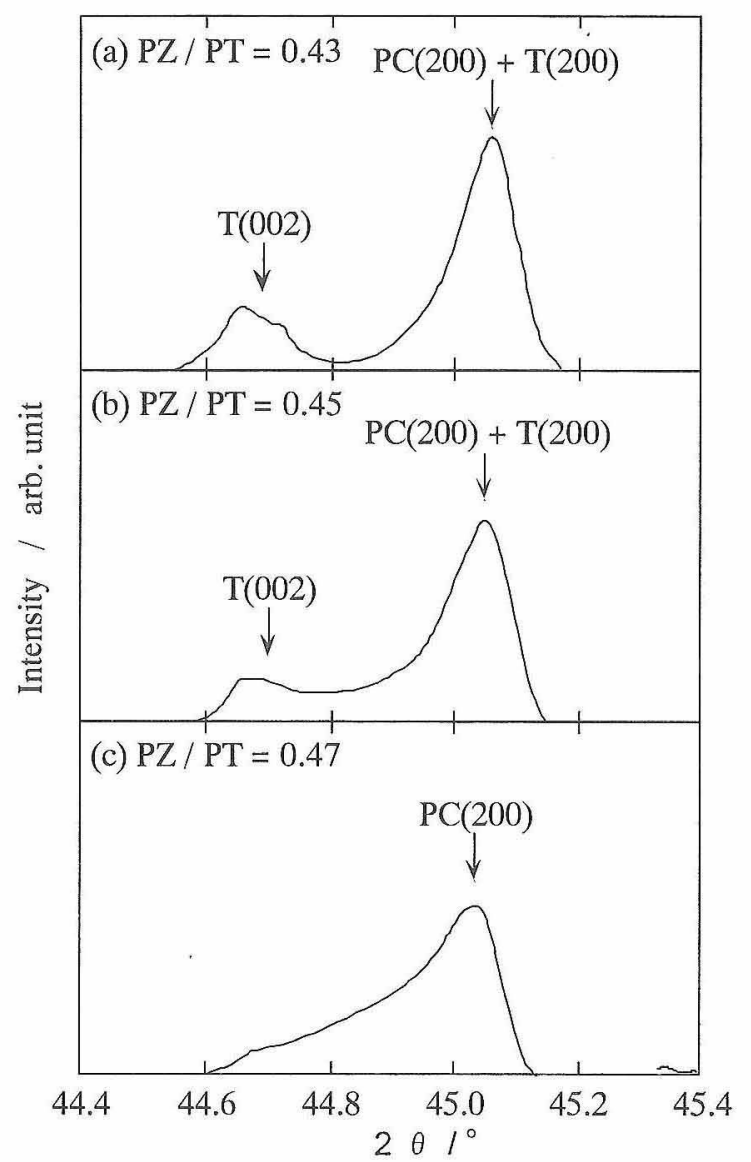

Fig. 1. Changes of XRD patterns of $\mathrm{PNN}-\mathrm{PZ}-\mathrm{PZ}$ powder (PNN =0.5) after the calcination at $1100^{\circ} \mathrm{C}$ for $3 \mathrm{~h}$ with $\mathrm{PZ} / \mathrm{PT}$ molar ratio, T: Tetragonal and PC: Pseudocubic.

peaks of $\mathrm{PNN}-\mathrm{PT}-\mathrm{PZ}$ powder $(\mathrm{PZ} / \mathrm{PT}=0.43,0.45$ and 0.47 ) calcined at $1100^{\circ} \mathrm{C}$ for $3 \mathrm{~h}$ again after the calcination at $850^{\circ} \mathrm{C}$ for $3 \mathrm{~h}$. The calcination at $1100^{\circ} \mathrm{C}$ was done to increase the crystallinity of PNN-PT-PZ powder. Each sample consists of both tetragonal and pseudocubic crystals. The peaks of the (002) tetragonal and (200) pseudocubic crystals overlapped, although the (200) peak of tetragonal crystal can be separated (Figs. 1(a) and (b)). However, the intensity of the peaks for the tetragonal (200) can be estimated because the intensity is almost two times larger than that of the (002) tetragonal crystal. The quantity of the tetragonal crystal phase decreases with the increase of PZ/PT molar ratio and that of the pseudocubic crystal phase increase with it. The quantity of the tetragonal is more than that of the pseudocubic with $\mathrm{PZ} / \mathrm{PT}=0.43$. However, the quantity of the pseudocubic with $\mathrm{PZ} /$ $\mathrm{PT}=0.45$ is more than that of $\mathrm{PZ} / \mathrm{PT}=0.43$. The tetragonal peak is diminished with $\mathrm{PZ} / \mathrm{PT}=0.47$. We believe that the PNN-PT-PZ ceramics with a composition of $\mathrm{PZ} / \mathrm{PT}=0.45$ was on the MPB, although the phase boundary is not entirely clear.

Figure 2 shows the microstructures of the fractured surface of the PNN-PT-PZ ceramics sintered in an air (hereafter specimen A) and a powder-bed method (hereafter specimen B). The density of specimen $A\left(8.14 \mathrm{~g} / \mathrm{cm}^{3}\right)$ is almost same as that of specimen $B\left(8.17 \mathrm{~g} / \mathrm{cm}^{3}\right)$ and it is considered that the effect of $k_{33}$ on the density of piezoelectric ceramics is negligible.

Each specimen shows pore-less and high density microstructure. It is thought that the PNN-PT-PZ powder sintered under a self-generated $\mathrm{PbO}$ atmosphere in air, be-
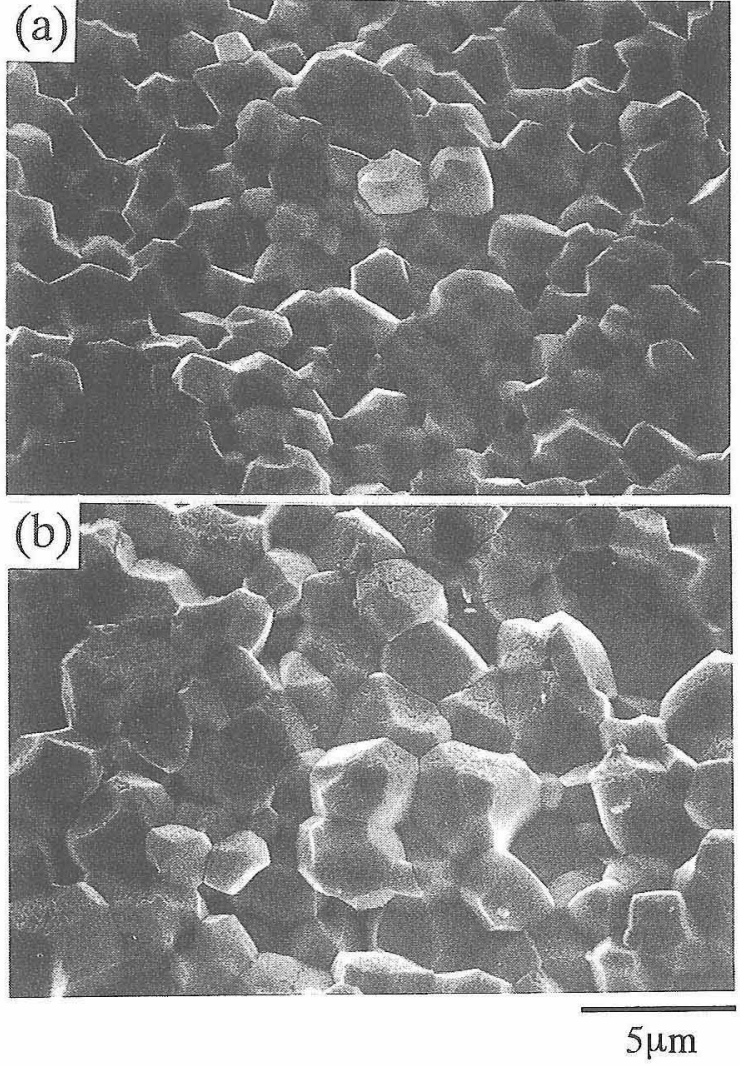

Fig. 2. Microstructures of fractured surfaces of PNN-PT-PZ piezoelectric ceramics sintered at $1100^{\circ} \mathrm{C}$ for $3 \mathrm{~h}$ in (a) air and (b) powder-bed.

cause the densities are relatively high. However, the average grain size of the specimen $B$ is larger than that of specimen $\mathrm{A}$. The $\mathrm{PbO}$ did not deposit on the surfaces of the specimens, because only a perovskite single phase was observed by XRD of the surfaces of specimens A and B.

For $\mathrm{Pb}$-based piezoelectric ceramics, the atmosphere oxygen partial pressure influenced the density. ${ }^{9), 10)}$ With a sintering temperature of around $1100^{\circ} \mathrm{C}$, the $\mathrm{PbO}$ vapor pressure evaporation-recondensation reaction is in equilibrium, ${ }^{11\}}$

$$
\mathrm{PbO} \leftrightarrows \mathrm{PbO} \text { (vapor) } \rightleftharpoons \mathrm{Pb}(\text { vapor })+1 / 2 \mathrm{O}_{2}
$$

Thus, the partial vapor pressure of oxygen in powder-bed sintering is higher than that in air. Kudo et al. reported that the grain growth of $\mathrm{Pb}$-based ceramics sintered in oxygen is also larger than that in air. ${ }^{10)}$ The small grain size of specimen $\mathrm{A}$ is probably due to lower $\mathrm{PbO}$ and oxygen partial pressure near the end of the sintering process. The $\mathrm{PbO}$ atmosphere significantly influenced to the grain growth process, although it does not influence to a lesser extent the densification in the sintering PNN-PT-PZ powder.

Figure 3 shows the changes of $k_{33}$ for the specimens $\mathrm{A}$ and $\mathrm{B}$ as a function of $\mathrm{PZ} / \mathrm{PT}$ molar ratio. The values of $k_{33}$ of specimen B are larger than those of specimen A with the same PZ/PT molar ratio. The values of $k_{33}$ of the specimens $\mathrm{A}$ and $\mathrm{B}$ show a maximum at $\mathrm{PZ} / \mathrm{PT}=0.45-0.475$. The maximum value of $k_{33}$ for specimen $\mathrm{B}$ is $80.8 \%$ with $\mathrm{PZ} /$ $\mathrm{PT}=0.45$. The molar ratio of $\mathrm{PZ} / \mathrm{PT}$ with a maximum of $k_{33}$ agreed with that of MPB in Fig. 1 . This value is the largest $k_{33}$ which has ever been reported except for single crystal ferroelectrics. ${ }^{12)}$ This high performance is due to carefully controlling the composition of specimen B near the MPB.

The composition with maximum $k_{33}$ value of sample $\mathrm{A}$ slightly differs from that of sample $B$. This reason is not 


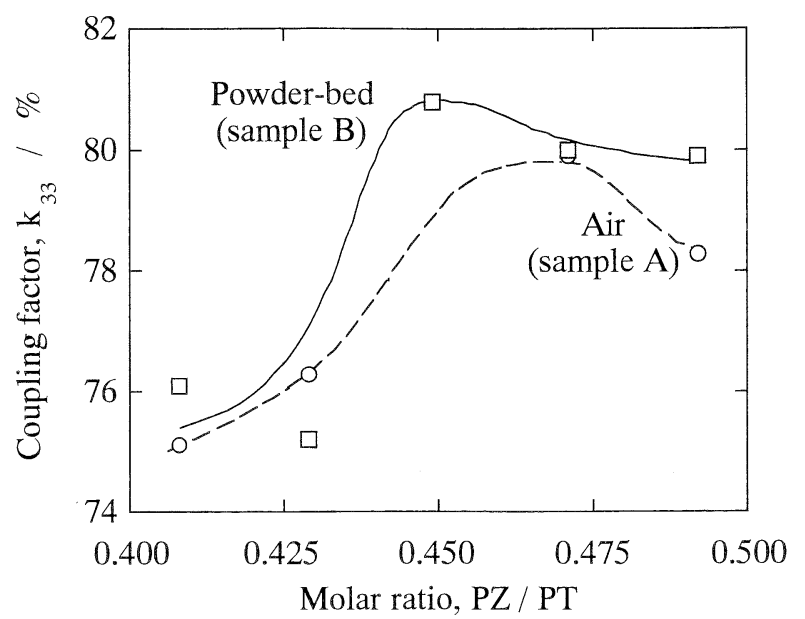

Fig. 3. Changes of coupling factors $\left(k_{33}\right)$ of PNN-PT-PZ $(\mathrm{PNN}=0.5)$ piezoelectric ceramics sintered in air and in a powderbed as a function of $\mathrm{PZ} / \mathrm{PT}$ molar ratio.

clear at present.

The maximum value of $k_{33}$ of sample $\mathrm{A}$ is smaller than that of sample B. The microstructure of ceramics influences on the coupling factor. The coupling factor of the piezoelectric ceramics having large grains is higher than that having small grains. ${ }^{10)}$ It is also supported that the coupling factor of piezoelectric single crystal is higher than that of ceramics. ${ }^{12)}$ Thus, the difference of maximum value of $k_{33}$ between the two types of sintering appears to be due to the size effect of the grains.

To summarize, the highest performance piezoelectric cer$\operatorname{amics}\left(k_{33}=80.8 \%\right)$ in PNN-PT-PZ system were produced in this study. The high $k_{33}$ appears to be due to the growth of the grain in the ceramic by powder-bed sintering method and to careful control of the composition of the ceramics near the MPB.

\section{References}

1) B. Jaffe, W. R. Cook, Jr. and H. Jaffe, "Piezoelectric Ceramics", Academic Press, New York (1971) pp. 7-21.

2) S. Takahashi, "Fine Ceramics", Ohmsha, Tokyo (1987) pp. 62-74.

3) L. Eyraud, P. Eyraud, P. Gonnard and M. Troccaz, Ferroelectrics, 31, 113-16 (1981).

4) H. Banno, T. Tsunooka and I. Shimano, Pro. 1st Meet. Ferroelectric Materals and Their Applications, Kyoto, Keihin Printing (1977) pp. 339-44.

5) D. Luff, R. Lane, K. R. Brown and H. J. Marshallsay, Trans. J. Br. Ceram. Soc., 73, 251-64 (1974).

6) N. Ichinose and M. Kimura, Jpn. J. Appl. Phys., 30, 2220-23 (1991).

7) J. H. Moon and H. M. Jang, J. Mater. Res., 8, 3184-91 (1993).

8) J. H. Moon and H. M. Jang, J. Am. Ceram. Soc., 76, 549-52 (1993).

9) P. GR. Lucuţa, FL. Constantinescu and D. Barb, J. Am. Ceram. Soc., 68, 533-37 (1985).

10) S. Kudo, S. Tashiro and H. Igarashi, Jpn. J. Appl. Phys., 34, 5303-05 (1995).

11) R. B. Atkin and R. M. Fulrath, J. Am. Ceram. Soc., 54, 26570 (1971).

12) J. Kuwata, K. Uchino and S. Nomura, Jpn. J. Appl. Phys., 21, 1298-302 (1982). 